\title{
Internet Gaming Disorder And Internet Addiction: Comparing Italian And Migrant Children And Adolescents
}

\section{Giulio Valtolina}

Catholic University of Milan

\section{Diego Boerchi}

Catholic University of Milan

Luca Milani ( $\square$ luca.milani@unicatt.it )

Catholic University of Milan

\section{Research Article}

Keywords: internet addiction, internet gaming disorder, migration, developmental risk.

Posted Date: February 16th, 2022

DOI: https://doi.org/10.21203/rs.3.rs-1306485/v1

License: (c) (i) This work is licensed under a Creative Commons Attribution 4.0 International License.

Read Full License 


\section{Abstract}

The DSM-5 has included Internet Gaming Disorder (IGD) as a potential new behavioral addiction related to some developmental risks such as depression, anxiety, attention disorders, social phobia, behavioral disorders, low academic performance. IGD stemmed from the previously proposed diagnosis of Internet Addiction (IA), which was also considered a behavioral addiction related to the Web's uncontrolled use and was correlated with maladaptive developmental outcomes. Literature shows a specific higher vulnerability of the migrant population to behavioral addictions - particularly gambling. Given this vulnerability and the amplitude of Italy's migration phenomenon, it is important to extend the knowledge about the risk of gaming and internet addiction to migrant adolescents and children in Italian schools. Thus, the aims of the present study are 1) to test the differences between Italian and migrant students in terms of problematic use of videogames and the Internet, and 2) to identify any risk factors predicting the emergence of problematic involvement in videogame activities and Internet use.

We administered a survey to 532 students (64.5\% females), aged between 9 and 20 years old ( $M=15.80$; DS $=2.16$ ), attending secondary schools of first and second grade in 4 Italian cities. $9.7 \%$ of the students declared that they do not have Italian citizenship.

The survey comprised specific instruments to measure Internet Gaming Disorder and Internet Addiction, respectively the VGA Questionnaire (VGA) and the Internet Addiction Test (IAT). Other instruments measured two areas of adaptation that literature highlighted as correlated to the two disorders: Coping strategies (assessed by the Children's Coping Strategies Checklist - Revised 1; CCSC-R1) and Interpersonal relations (measured by Interpersonal Relationship Test; TRI).

Results indicate that the migrant condition can be a risk factor for IGD and IA, mainly when associated with avoidant coping strategies. Better interpersonal relations with female and male peers can be potential protective factors that counterbalance addiction risk.

Implications point to fostering inclusion interventions aimed to migrant children to reduce the risk of gaming addiction in this specific group.

\section{Introduction}

Almost 4.54 billion people are nowadays connected to the Internet, and about half of the world's population, 3.8 billion people, regularly use social networks, an increase of about $9 \%$ compared to 2019 (Digital, 2020). According to ISTAT data (2019), 76.1 of households in Italy have Internet access, and almost all 15-24-year-old browse the Web (over 90\%), with lower rates of access among later age groups. The Covid-19 pandemic has also widened the digital divide between those included and those excluded from the community network (Beaunoyer et al., 2020).

Over the last 15 years, research on new technologies addiction has increased exponentially, although the phenomenon of Internet Addiction (IA) has not yet been unequivocally outlined (cf. Yellowlees \& Marks, 
2007). Due to the widespread use of the Internet, especially among young people, research on IA has focused on adolescents, stressing individual and relational risk factors. More specifically, the most at-risk youngsters show low social openness, reduced emotional intelligence, and a liking for secluded activities (Young \& Rodgers, 1998; Kircaburun et al., 2020). Other risk factors are a high level of perceived loneliness (Morahan-Martin \& Schumacher, 2000) and the presence of depressive traits with suicidal ideation (Kraut et al., 1998; Yu et al., 2020). In this respect, Caplan (2007) introduced the term "Preference for Online Social Interaction" (POSI) in order to describe adolescents perceiving themselves as safer, more effective, more confident, and more comfortable in online interaction than in traditional face-to-face interactions. A recent study investigated the relationship among social anxiety, motivation, and POSI and suggested that metacognitions may play an essential role in the association between social anxiety and Internet Gaming Disorder (IGD), along with POSI (Marino et al., 2020). Moreover, a permissive parenting style can be included in environmental risk factors (Maftei \& Enea, 2020).

IA's worldwide prevalence is reported to be around $6 \%$, with peaks of $10.9 \%$ in the Far East and lower rates in Europe (2.6\%; cf. Cheng \& Li, 2014). Another analysis focused on the prevalence rates of IA and gaming disorders in Southeast Asia revealed an aggregate prevalence rate of $20 \%$ for IA and $10.1 \%$ for IGD (Chia et al., 2020).

In terms of developmental outcomes, the disorder has been associated with: identity shortfalls (Kim et al., 2012), brain structure alterations (Lin et al., 2012; Wang et al. (2020), impairments in cognitive functioning (Park et al., 2011), risk-seeking behavior (Tsitsika et al., 2011; Dong \& Potenza, 2016), low quality of interpersonal relationships (Milani, Osualdella, \& Di Blasio, 2009), eating disorders (Kim et al., 2010; Hadwiger et al., 2019), internalizing symptoms (Pace, D'Urso, \& Zappulla, 2019) and self-harming behavior (Lam et al., 2009; Tang et al., 2020).

DSM-5 introduced the diagnosis of IGD in the third section of the manual, which partly included some of Internet Addiction characteristics. IGD is defined as a form of pathological video game addiction with characteristics typical of behavioral addictions (Kuss \& Griffiths, 2012), characterized by nine diagnostic criteria, such as abstinence, tolerance, loss of control over gaming behavior, use of games in order to shun unpleasant emotional states, jeopardizing of a relationship, an educational or work opportunity because of the gaming habits.

\section{Internet Gaming Disorder: prevalence and patterns}

Video gaming is a hobby enjoyed by young and old across the globe. In 2020, there were an estimated 2.7 billion gamers across the world (Newzoo, 2020). There were almost 1.5 billion gamers in the Asia Pacific region, making it the largest for video gaming worldwide. In Europe, they were 386 million, making it the second-largest region for video gaming. In Italy, according to a survey conducted by IIDEA (Italian Interactive Digital Entertainment Association) in 2019, people who used video games were $39 \%$ of the entire population aged between 6 and 64 years, playing on average 7.4 hours per week. The most used gaming platforms are mobile devices such as smartphones and tablets. In youngsters aged $11-14,26 \%$ 
use handheld consoles, $41 \%$ computers, $49 \%$ tablets, $53 \%$ smartphones, and $64 \%$ consoles (Italian Interactive Digital Entertainment Association, 2020).

Research investigating the prevalence of Internet Gaming Disorder (IGD) shows it is higher for males (Wartberg, Kriston, Thomasius, 2020), and it is more widespread in Asian countries (Van Rooij et al., 2014; Chia et al. 2020). The prevalence appears to range between $3.4 \%$ and $6.4 \%$, with a high discrepancy between males (6.8\%) and females (1.3\%) (Fam, 2018). The highest prevalence was found in the Asian population: $17.5 \%$ for male adolescents and $7.9 \%$ for female adolescents (Jang et al., 2020). Early Italian data (Milani et al. 2018) indicate a prevalence of subthreshold risk ( 3 out of 9 symptoms) in $15.2 \%$ and diagnosis (5 out of 9 symptoms) in $2.1 \%$. The data also indicate a different prevalence according to gender: males seem to be more at risk for IGD, females seem to be more vulnerable to IA.

Although the time spent gambling is a potential risk factor for addiction development, this is not a diagnostic criterion. There is a consensus that addicted gamblers spend more time gambling than the control population (cf. Gentile et al., 2011; Lemmens \& Hendriks, 2016). However, more than the time itself, a more relevant risk factor seems to be the gaming habits, i.e., gaming sessions at unusual times of the day (at night during the working week; Triberti et al., 2018; Musetti et al., 2019).

Other risk factors not related to gaming that may influence IGD development appear to be male gender (Van Rooij et al., 2014; Su et al., 2020), neuroticism as a personality trait (Wang, Ho, Chan, \& Tse, 2015; Gonzáles-Bueso et al., 2020), inclination to aggressiveness and acceptance of violence (Müller et al., 2015; Jeong et al., 2020; Paulus et al., 2018). Other research highlights the following among the risk factors associated with IGD: online relationship and friendship seeking (Caplan, Williams, \& Yee, 2009; Kardefelt-Winther, 2014), immersion and dissociation seeking (Snodgrass, Dengah, Lacy, \& Fagan, 2013; Snodgrass et al., 2018), use of the game as a coping and escape strategy from everyday stressors and negative emotions (Cole \& Hooley, 2013; King, Delfabbro, \& Griffiths, 2011; Kuss, Louws, \& Wiers, 2012; Li, Liau, \& Khoo, 2011; Milani et al., 2018).

About consequences of IGD in terms of maladaptive outcomes, the literature shows that youths at risk of gaming addiction tend to prefer mediated and virtual relationships over face-to-face ones (Hussain \& Griffiths, 2009) and are characterized by behavioral problems (Brunborg et al., 2014), ADHD (Kim et al., 2020; Chang et al., 2020), low performance at school (Jeong \& Kim, 2011; Sugaya et al. (2019), risk of alcohol and substance abuse (Van Rooij et al., 2014; Wenzel, Bakken, Johansson, Götestam \& Øren, 2009).

Finally, concerning symptomatology, there is evidence of an association between IGD and depressive and mood-deflection signs (Brunborg et al. 2014, Van Rooij et al. 2014; Wenzel, Bakken, Johansson, Götestam \& Øren, 2009; Ostinelli et al., 2021), symptoms related to anxiety and panic disorders (Cole \& Hooley, 2013; Rehbein et al., 2010; Walther, Morgenstern \& Hanewinkel, 2012; Wang et al. (2017), low self-esteem (Lemmens, Valkenburg \& Peter, 2011; Wartberg et al., 2019), somatization (Allison et al. 2006; Dworak, Schierl, Bruns, Struder, 2007; Cerniglia et al., 2019), impulsivity (Walther et al., 2012; Hu et al., 2017), 
irritability and aggressiveness (Ko et al., 2009; Milani et al., 2018), as well as ADHD (Batthyány, Müller, Benker \& Wölfling, 2009; Evren et al., 2019).

\section{Migratory background and developmental risk}

The significance of ethnicity in migrant children's development is substantial (Valtolina, 2013). Ethnic belonging is related to all physiological and psychological changes of human development, mainly affecting family and peer relationships (Henneberger et al., 2016; Graham \& Echols, 2018). So, although with significant differences depending on several variables (place of birth, country of origin, integration, family aim, etc.), children with the migratory background are thought to be at significant developmental risk, with psychological distress and risk-taking behaviors, such as smoking, drinking, drug addiction, IA (Kouider, Koglin \& Petermann, 2014; Nakash et al., 2012).

Several studies (Verkuyten, 1998; Pascoe \& Richman, 2009; Bilgin, 2017; Giuliani, Tagliabue \& Regalia, 2018; Motto-Stefanidi, Pavlopoulos \& Asendorpf, 2018) highlight how migrant children are often discriminated, with negative implications for their development and psychological well-being. Moreover, other elements are relevant: the effects of migration trauma, such as the stress resulting from the loss of family and friends, the radical change of daily habits; the acculturation stress (Berry, 2006), i.e., the stress resulting from dealing with a new culture, very often completely different from the family culture (Guarnaccia \& Lopez, 1998; Stevens \& Vollebergh, 2008; Walsh, Shulman, \& Maurer, 2008; Kien et al., 2018). The stress associated with the acculturation process can lead some youngsters to increase risk behaviors (Barbato et al., 2013; Boerchi, 2014; Cristini et al., 2015; Betancourt, Frounfelker, Mishra, Hussein \& Falzarano, 2015; Motto-Stefanidi, 2018).

So, as some scholars did (Canale et al., 2017), it could be said that adolescents with a migrant background show more behavioral problems than native adolescents, also regarding IGD. Although this phenomenon's nosological classification is still a matter of debate, it is argued that IGD might be described as a non-substance-related addiction. Epidemiological surveys reveal that it affects up to $3 \%$ of adolescents and seems to be related to psychosocial symptoms (Müller et al., 2015).

IGD and IA are not exclusive to offspring of migrant parents, but also migrant unaccompanied minors, a significant portion of the migratory flow towards Europe, mainly in recent years (Valtolina \& Boerchi, 2019).

Since several studies highlighted the vulnerability of migrants to behavioral addiction such as gambling disorder (Stinchfield, 2000; Ellenbogen, Gupta, \& Derevensky, 2007; Hayer \& Griffiths, 2016; Canale et al., 2017; Gainsbury, 2017; Wardle et al., 2019), it is crucial to assess whether this vulnerability also includes technological dependencies.

Furthermore, it should be considered that gaming addiction is chronic: Gentile et al. (2011) emphasized that over $80 \%$ of pathological gamers are out of control for at least two years. Therefore, video game addiction is an issue that needs to be further investigated, especially in young people with a migrant background, due to its severe consequences on development and mental health. 


\section{The Present Study}

The study here presented intends to collect preliminary data on the prevalence of technological addictions in a population of students with a migratory background compared to Italian ones and identify possible maladaptive correlations of the disorders. For the research, we decided to verify both the prevalence and characteristics of IGD - a diagnosis consolidated in the literature and present in the DSM5 - and the Internet Addiction construct, as it is still widely considered even in the academic field.

The study's objectives can be summarized as follows:

- testing the differences between Italian and migrant students in terms of problematic use of videogames and the Internet:

- identifying any risk factors predicting the emergence of problematic involvement in videogame activities and Internet use.

The present study intends to investigate both the differences in the distribution of addictions between students with Italian citizenship (ITA) and those without Italian citizenship (WIC) as well as between males and females and the role coping strategies and interpersonal relationships can play in increasing addiction to video games and the Internet.

\section{Hypotheses}

More precisely, we will test the following hypotheses, formulated following the literature on the subject:

1) WIC students' scores in terms of IGD and Internet addiction will be higher than ITA students' scores;

2) male students' scores for IGD will be higher than females students' scores, while female students' score for Internet addiction will be higher than male students' scores;

3) male and female students' scores about IGD and Internet addiction will not be different regarding their citizenship;

4) both IGD and Internet addiction scores will increase with age;

5) maladaptive coping strategies will contribute to predict both IGD and Internet addiction;

6) the quality of interpersonal relationships will contribute to contrast IGD and Internet addictions.

\section{Participants}

532 students participated in the study. After controlling for outliers with the Mahalanobis method, 14 of them (2.6\%) were not considered for the following analysis. Age ranged from 9 to 20 y.o. $(M=15.80 ; D S=$ 2.161) attending different types and orders of schools in four big Italian cities (Brescia, Milano, Roma, and Verona). Gender was not equally distributed, with females more represented than males ( $F=64.5 \%$; 
$M=35.5 \%)$. Fifty students (9.7\%) had no Italian citizenship, 18 originating in Europe and 32 in ExtraEuropean countries. ITA and WIC groups were similar by age $(t(516)=-1.526, p=.128)$, and gender $\left(\chi^{2}(1)\right.$ $=.006, \mathrm{p}=.941)$.

\section{Measures}

Participants compiled the following questionnaires:

- Revised Video Games Addiction Questionnaire (VGA; Gentile et al., 2012), composed of 16 items on a 3point Likert scale, aimed to identify the possible presence of problematic and uncontrolled use of video games (both online and offline). Cronbach's Alpha was acceptable $(a=.71)$.

- Internet Addiction Test (IAT, Young, 1998), composed of 20 items on a 5-point Likert scale, aimed to investigate how the use of the Internet can affect social life, academic and job career quality, and time control. Cronbach's Alpha was good $(a=.89)$.

- Children's Coping Strategies Checklist (CCSC, Ayers \& Sandler, 1999; Italian adaptation of Camisasca et al., 2012), composed of 54 items on a 4-point Likert scale, aimed to test children and adolescents' ability to cope with stress by mean of the use of cognitive coping strategies (active coping, distraction strategies, avoidance strategies, support seeking strategies). Cronbach's Alpha was excellent $(a=.90)$.

Assessment of Interpersonal Relations (AIR, Bracken, 1997) measures adolescents' interpersonal competence in relationships with peers and with adult figures. The questionnaire comprises five subscales (relationship with the mother, with the father, with the female peers, with the male peers, and with the teachers) composed of the same 35 items on a 4-point Likert scale. Cronbach's Alpha was excellent $(a=.95)$.

\section{Procedure}

The study was presented to the students indicating that its goal was to investigate their behaviors related to video games and the use of the Internet, and how they deal with life events and people closest to them. Subsequently, their parents were given a letter of presentation of the study and a form to collect their informed consent signed by both parents. The questionnaire's administration to the students took place in group mode in the classrooms and during school hours. Participation was voluntary, and participants were informed of the possibility of withdrawing from the collaboration at any time. Data was collected prior to the Covid-19 pandemic.

\section{Data analysis}

The first three hypotheses were tested by the Analysis of the Variance, separately for IGD and IA, considering nationality and gender interactions.

A path analysis model tested the remaining hypotheses with coping strategies, quality of the relationships, age, and gender correlating themselves and affecting IGD and IA separately. 
We tested the metric measurement invariance (Steenkamp, \& Baumgartner, 1998) of the ITA and WIC models through multigroup CFAs with the maximum likelihood method and AMOS software to test if the factor loadings were equal in ITA and WIC groups. We compared fit indexes to test if the two models were not different. $\Delta \chi 2$ should not be significant, $\Delta C F I$ should be lower than .010 (Chen, 2007). Because the model had zero degrees of freedom for the unconstrained model, $\chi 2$ was zero, and CFI was one.

Even if, due to the small size of the WIC group, some analyses were not statistically significant, we believe that, in line with the ASA's statement on p-values (Wasserstein \& Lazar, 2016), the conditions exist to consider useful some of the results obtained for the scientific debate.

\section{Results}

The first three hypotheses were almost entirely confirmed (Tables 1 and 2). The data partially confirmed the first one: WIC group showed to be more video game addicted than ITA group, while no significant difference was found on Internet addiction. The second hypothesis was confirmed: male students tend to be more video game addicted while female students tend to be more Interned addicted. Also, the third hypothesis was confirmed: males' and females' risk of either addiction seems not to be related to the nationality.

Table 1

ANOVA of Internet Gaming Disorder by Nationality and Gender

\begin{tabular}{|c|c|c|c|c|}
\hline & Mean & SD & $F^{(d f)}$ & $p$ \\
\hline Male & 1.66 & 1.575 & \multirow[t]{2}{*}{$5.744^{(1)}$} & \multirow[t]{2}{*}{.017} \\
\hline Female & 1.15 & 1.310 & & \\
\hline ITA & 1.26 & 1.347 & \multirow[t]{2}{*}{$12.422^{(1)}$} & \multirow[t]{2}{*}{.000} \\
\hline WIC & 2.02 & 3.714 & & \\
\hline Gender x Nationality & & & $.005^{(1)}$ & .945 \\
\hline
\end{tabular}

Table 2

ANOVA of the Internet Addiction by Nationality and Gender

\begin{tabular}{|lllll|}
\hline & Mean & SD & $F^{\text {(df) }}$ & P \\
\cline { 1 - 4 } Male & 29.17 & 15.090 & $4.449^{(1)}$ & .035 \\
Female & 34.03 & 14.520 & & \\
ITA & 32.21 & 14.786 & $.189^{(1)}$ & .664 \\
WIC & 33.16 & 15.998 & & \\
\cline { 1 - 5 } Gender x Nationality & & & $.001^{(1)}$ & .980 \\
\hline
\end{tabular}


The IGD path analysis explained the $11 \%$ of the ITA group variance and the $15 \%$ of the variance for the WIC group. Results confirmed that male students tended to be more addicted and showed that the risk to develop an IGD is higher with students adopting Avoidance coping and lower for those adopting Active coping; at the opposite, no one relation was found between the different types of relationships and the VGA (Table 3). However, higher scores of relationships with male peers seem to be marginally significant in protecting against IGD. Even if the WIC group's regression weights were not statistically significant, because, at the metric invariance level, the two groups behaved at the same way, it is likely the relations exist, and they are the same in both of them $(\Delta \chi 2(11)=5.591, p=.899 ; \Delta C F I=.000)$.

Table 3

Standardized Regression Weights of the Video Game Addiction's predictors

\begin{tabular}{|lllll|}
\hline & ITA & \multicolumn{3}{l|}{ WIC } \\
\hline & $\boldsymbol{\beta}$ & $\mathbf{p}$ & $\boldsymbol{\beta}$ & $\mathbf{P}$ \\
\hline Age & -.050 & .256 & -.090 & .577 \\
\hline Gender & -.176 & .000 & -.173 & .339 \\
\hline Active Coping & -.124 & .032 & .133 & .436 \\
\hline Distraction Coping & .076 & .122 & -.075 & .611 \\
\hline Avoidance Coping & .219 & .000 & .208 & .172 \\
\hline Support Seeking Coping & .052 & .327 & .070 & .677 \\
\hline Relationship with the mother & .116 & .085 & -.061 & .788 \\
\hline Relationship with the father & .013 & .836 & .177 & .395 \\
\hline Relationship with male peers & -.103 & .052 & .199 & .376 \\
\hline Relationship with female peers & -.011 & .849 & -.262 & .285 \\
\hline Relationship with teachers & .062 & .184 & -.104 & .544 \\
\hline Significant Standardized Regression Weights are in bold. & \\
\hline
\end{tabular}

The Internet Addiction path analysis explained the $17 \%$ variance for ITA group and the $25 \%$ variance for the WIC group. Results confirmed that female students tended to be more Internet-addicted than males and that this phenomenon tends to increase with increasing age, but just for the ITA group. The risk to develop the IA is higher with students adopting Avoidance coping and lower for those adopting Active coping, even if data were not statistically significant. Moreover, it tends to increase for students having bad relationships with females in the ITA group and having bad relationships with males and good relationships with teachers for WIC group, even if data are not statistically significant (Table 4). Instead of the differences on these last variables, also, in this case, the metric invariance level of the two samples was not statistically significant $(\Delta \chi 2(11)=7.568, p=.751 ; \Delta C F I=.000)$. 
Table 4

Standardized Regression Weights of the Internet Addiction's predictors

\begin{tabular}{|lcccc|}
\hline & ITA & \multicolumn{3}{l|}{ WIC } \\
\hline & $\boldsymbol{\beta}$ & $\mathbf{p}$ & $\boldsymbol{\beta}$ & $\mathbf{p}$ \\
\hline Age & .207 & .000 & -.029 & .850 \\
\hline Gender & .091 & .040 & .078 & .646 \\
\hline Active Coping & -.108 & .054 & .179 & .264 \\
\hline Distraction Coping & .017 & .721 & .016 & .906 \\
\hline Avoidance Coping & .235 & .000 & .282 & .048 \\
\hline Support Seeking Coping & -.015 & .768 & -.003 & .986 \\
\hline Relationship with the mother & -.011 & .864 & -.004 & .984 \\
\hline Relationship with the father & -.004 & .950 & -.075 & .701 \\
\hline Relationship with male peers & -.037 & .468 & -.229 & .279 \\
\hline Relationship with female peers & -.175 & .003 & -.026 & .909 \\
\hline Relationship with teachers & .031 & .497 & .231 & .151 \\
\hline Significant Standardized Regression Weights are in bold. & \\
\hline
\end{tabular}

Hypothesis four was confirmed just for IA and ITA groups. Hypothesis five was confirmed for both the groups limiting to Avoidance coping and hypothesis six was partially confirmed and differently for the two groups.

\section{Discussion}

Results of the research seem to support some of the hypotheses. In particular, it seems that students without Italian citizenship are more at risk of developing Internet Gaming Disorder than their Italian peers (H1), but not Internet addiction. As also highlighted by previous literature, our results point out that males are more at risk of IGD than females, and females, on the other hand, seem to be more at risk of Internet addiction $(\mathrm{H} 2)$. These gender differences seem to be unrelated to being Italian or without Italian citizenship, providing further support to the increased risk of IGD for boys and increased IA risk for girls $(\mathrm{H} 3)$.

Moving to hypotheses 4, 5 and 6, path analysis models show that - on the whole - age and maladaptive coping strategies are associated with a higher risk of IGD and Internet addiction. In comparison, the quality of relationships (especially with female peers) seems to be associated with a lower risk of Internet addiction. Considering the low number of WIC students and the invariance between Italian and non-Italian 
path analysis models, we believe that with a bigger sample, the results of WIC students would have been significant. Thus, results hold some points of interest for scientific debate, given the dearth of studies addressing the risk of technological addiction among migrant populations.

Connecting with the relevant literature, we can argue that, following Dreier and colleagues (2017), youth at risk for technology addiction seem to use media as a mean to regulate negative feelings and to cope with problems (e.g., by immersing in a video game as a mean to escape the disturbing thoughts). This tendency is more evident when adolescents are characterized by a preference for maladaptive coping strategies such as avoidance and distraction (Loton et al., 2016). Kuss and colleagues (2012) argued that this tendency is reinforced by escapism as a cognitive style. Our results point in this direction, highlighting as avoidance is a predictor of both IGD and Internet addiction. On the contrary, counting on effective strategies, such as Active coping, seem to exert a protective effect against the risk of addiction.

The results of this research seem to point out - as a general consideration - that students with a migrant background could be at higher risk for technological addiction, probably as a way to escape problems and distress experimented into daily routines. The dearth mentioned above of research on this issue concur that migrant adolescents are at a higher risk of developing behavioral addictions such as gambling disorder (Gainsbury, 2017; Wardle et al., 2019; Ellenbogen, Gupta, \& Derevensky, 2007; Canale et al., 2017). The risk of technological addiction could likely be based upon the quality of interpersonal relations of the adolescent. Both models show that having better relations with male peers (tendency to significance in the IGD model) and with female peers (Internet addiction model) exert a protective effect against the risk of addiction.

In this light, it is essential to note that the research on migrant experience highlight that migration is a highly stressful process, which requires a specific effort to be elaborated and included in the personal story of life (Yakushko, Watson \& Thompson, 2008; Tabor \& Milfont, 2011). Regarding adolescents with a migrant background, many authors consider the "second generation" as the population at a higher risk of maladaptive outcomes and social isolation (Neto, 1996; Portes \& Rumbaut, 2001; 2005). This may lead them to recur to online-only relations in the attempt to overcome the lack of those fine social skills required to embed into a different culture successfully. As previously shown, the tendency to recur to online interactions (Preference for Online Social Interaction, or POSI) could lead these adolescents to selfselect their relations, opting to value especially those that can be pursued online as a mean to preserve their social capital, at the expense of a higher risk of addiction (Casale, Tella, \& Fioravanti, 2013). Studies about social marginality show that the ethnic identity of many minors with a migrant background is becoming more and more "symbolic" (Gans, 2009), namely that ethnicity can survive without significant social or cultural participation, rejecting an active ethnicity. Symbolic ethnicity is a nostalgic loyalty, love, and pride in a cultural tradition that can be felt and experienced without being part of everyday behavior. Thus, recurring online-mediated relations may increase the risk of a problematic process of identity formation. 
Of particular interest is that our data were collected before the Covid-19 pandemic and shed a distinctive light about the risk of technological addiction related to the migrant background. Research about technological addiction in the Covid-19 emergency shows that the rates of usage of digital media are increased by the distancing, with a likely parallel increase of the prevalence of addiction (e.g., Paschke et al., 2021; Sun et al., 2020) and psychological distress, as a result, is increased (Servidio et al., 2021).

To conclude, these research results seem to point out that girls and boys with a migrant background are at a higher risk of technological addiction, especially considering as these technologies are readily available and characterized by ease of use.

In our opinion, a special effort should be addressed to propose specific interventions about media literacy in order to favor a healthy approach to new technologies by adolescents. This holds truer in the light of the high prevalence of technology-mediated activities due to the Covid-19 pandemic. Parallel efforts should be addressed to parents to make them aware of the risks related to the uncontrolled use of technologies and promote active parental mediation of new technology use.

\section{Limitations And Future Directions}

The present study has several limits that need to be acknowledged and amended in future research.

First, the method is cross-sectional, thus limiting the possibility to ascertain the causal relationship between variables. For example, the results make it possible to assume that Avoidance coping predicts technological addiction. However, it may be that the opposite relation is true (i.e., being dependent upon technology "deactivates" more adaptive strategies such as Active coping or Support Seeking coping by lack of use). Longitudinal studies will be needed better to clarify the direction of causality between the variables.

Second, the research method is single-informant. This means that adolescents may be induced to alter their answers out of social desirability, hindering the results' reliability. Future research should adopt a cross-informant method to overcome this limitation.

Notwithstanding these limitations, we believe that this research's preliminary results shed some light on the specific risk of technological addiction of adolescents with a migrant background and draw researchers and professionals' attention to this specific population of youth.

\section{Declarations}

\section{Funding}

No funding was received for the research here presented.

\section{Conflict of interests}


On behalf of all authors, the corresponding author states that there is no conflict of interest.

\section{Availability of data and material}

The manuscript has no associated data.

\section{Ethical statement}

The research has been evaluated and approved by the Ethical Commission of the Department of Psychology of the Catholic University of Milan. All methods were performed in accordance with the Helsinky Declaration regarding research with human subjects.

\section{References}

1. Allison, S. E., von Wahlde, L., Shockley, T., \& Gabbard, G. O. (2006). The development of the self in the era of the Internet and role-playing fantasy games. The American Journal of Psychiatry, 163, 3, 381385.

2. Ayers, T. S., \& Sandler, I. N. (2009). Manual for the children's coping strategies checklist \& the how I coped under pressure scale. Tempe: Arizona State University.

3. Barbato, M. C., Cristini, F., Scacchi, L., \& Santinello, M. (2013). Adolescenti immigrati e comportamenti antisociali: maggiore o minore rischio?. Psicoterapia Cognitiva e Comportamentale, 19, 2, 169-190.

4. Batthyány, D., Müller, K. W., Benker, F., \& Wölfling, K. (2009). Computer game playing: Clinical characteristics of dependence and abuse among adolescents. Wiener Klinische Wochenschrift, 121, $15,502-509$.

5. Beaunoyer, E., Dupéré, S., \& Guitton, M. J. (2020). COVID-19 and digital inequalities: Reciprocal impacts and mitigation strategies. Computers in human behavior, 111, 106424. doi.org/10.1016/j.chb.2020.106424.

6. Berry, J. W. (2006). Acculturative stress. In Handbook of multicultural perspectives on stress and coping (pp. 287-298). New York: Springer.

7. Betancourt, T. S., Frounfelker, R., Mishra, T., Hussein, A. \& Falzarano, R. (2015). Addressing health disparities in the mental health of refugee children and adolescents through community-based participatory research: a study in 2 communities. American Journal of Public Health, 105(S3), 475482.

8. Bilgin, I. (2017). The consequences of perceived discrimination on internalizing mental health outcomes for immigrant adolescents in OECD countries: A systematic literature review. Disponibile online: https://pdfs.semanticscho lar.org/5ea6/9b1a7bf1768228864988d468cc980aeedb15.pdf? _ga=2.199160047.1536213142.1578318323-1788499549.1578318323

9. Boerchi, D. (2014), La scelta scolastica degli studenti immigrati di seconda generazione, Studi Emigrazione/Migration Studies, 51, 195, 427-444.

10. Bracken, B. A. (1997). Test TRl: test delle relazioni interpersonali. Erickson. 
11. Brunborg, G. S., Mentzoni, R. A., \& Frøyland, L. R. (2014). Is video gaming, or video game addiction, associated with depression, academic achievement, heavy episodic drinking, or conduct problems? Journal of Behavioral Addictions, 3, 1, 27-32.

12. Camisasca, E., Caravita, S., Milani, L., \& Di Blasio, P. (2012). The Children's Coping Strategies Checklist-Revision1: A validation study in the Italian population. TPM: Testing, Psychometrics, Methodology in Applied Psychology, 19(3).

13. Canale, N., Vieno, A., Griffiths, M. D., Borraccino, A., Lazzeri, G., Charrier, L. \& Santinello, M. (2017). A large-scale national study of gambling severity among immigrant and non-immigrant adolescents: the role of the family. Addictive behaviors, 66, 125-131.

14. Caplan, S. E. (2007). Relations Among Loneliness, Social Anxiety, and Problematic Internet Use. Cyberpsychology \& Behavior, 10(2), 234-242.

15. Caplan, S., Williams, D. \& Yee, N. (2009). Problematic Internet use and psychosocial well-being among MMO players. Computers in Human Behavior, 25, 6, 1312-1319.

16. Casale, S., Tella, L., \& Fioravanti, G. (2013). Preference for online social interactions among young people: Direct and indirect effects of emotional intelligence. Personality and Individual Differences, 54(4), 524-529.

17. Cerniglia L., Guicciardi M., Sinatra M., Monacis L., Simonelli A., Cimino S. (2019). The Use of Digital Technologies, Impulsivity and Psychopathological Symptoms in Adolescence. Behavioral Sciences, 9:82. doi: $10.3390 /$ bs 9080082

18. Chan, P. A. \& Rabinowitz, T. (2006). A cross-sectional analysis of video games and attention deficit hyperactivity disorders symptoms in adolescents. Annals of General Psychiatry, 5, 1, 16-26.

19. Chang C.H., Chang Y.C., Cheng H. \& Tzang R.F. (2020). Treatment efficacy of internet gaming disorder with attention deficit hyperactivity disorder and emotional dysregulation. International Journal of neuropsychopharmacology, 23, 6, pp. 349-355.

20. Chen, F. F. (2007). Sensitivity of goodness of fit indexes to lack of measurement invariance. Structural Equation Model, 14, 464-504.

21. Cheng, C., \& Li, A. Y. L. (2014). Internet addiction prevalence and quality of (real) life: A meta-analysis of 31 nations across seven world regions. Cyberpsychology, Behavior, and Social Networking, 17(12), 755-760.

22. Chia, D.X.Y., Ng C.W.L., Kandasami, G., Seow, M. Y., Choo, C. C., Chew, P. K. H., Lee, C., Zhang, M. W. B. (2020). International Journal of Environmental Research and Public Health, 17, 7, 1-17.

23. Choo, H., Gentile, D. A., Sim, T., Li, D., Khoo, A., \& Liau, A. K. (2010). Pathological video-gaming among Singaporean youth. Annals Academy of Medicine, 39, 11, 822-829. Disponibile online: http://www.annals.edu.sg/pdf/39VolNo11Nov2010/V39N11p822.pdf

24. Cole, S. H., \& Hooley, J. M. (2013). Clinical and Personality Correlates of MMO Gaming: Anxiety and Absorption in Problematic Internet Use. Social Science Computer Review, 31, 4, 424-436.

25. Cristini, F., Scacchi, L., Perkins, D. D., Bless, K. D., \& Vieno, A. (2015). Drug use among immigrant and non-immigrant adolescents: immigrant paradox, family and peer influences. Journal of Community 
and Applied Social Psychology, 25, 6, 531-548.

26. Digital (2020). Report Digital 2020: lo scenario nel mondo e in Italia. Available online: https://www.digitaldictionary.it/blog/report-digital-2020-scenario-digitale-mondo-e-italia.

27. Dong, G., \& Potenza, M. (2016). Risk-taking and risky decision-making in Internet gaming disorder: Implications regarding online gaming in the setting of negative consequences. Journal of Psychiatric Research, 73, 1-8. doi: 10.1016/j.jpsychires.2015.11.0110022-3956.

28. Dreier, M., Wölfling, K., Duven, E., Giralt, S., Beutel, M. E., \& Müller, K. W. (2017). Free-to-play: about addicted whales, at risk dolphins and healthy minnows.Monetarization design and Internet gaming disorder. Addictive Behaviors, 64, 328-333.

29. Dworak, M., Schierl, T., Bruns, T., \& Struder, H. K. (2007). Impact of singular excessive computer game and television exposure on sleep patterns and memory performance of school-aged children. Pediatrics, 120, 5, 978-985.

30. Ellenbogen, S., Gupta, R., \& Derevensky, J. L. (2007). A cross-cultural study of gambling behaviour among adolescents. Journal of Gambling Studies, 23(1), 25-39.

31. Evren C., Evren B., Dalbudak E., Topcu M., Kutlu N. (2019). Relationships of Internet addiction and Internet gaming disorder symptom severities with probable attention deficit/hyperactivity disorder, aggression and negative affect among university students. ADHD Attention Deficit and Hyperactivity Disorders, 11, 413-421. doi: 10.1007/s12402-019-00305-8.

32. Fam, J. Y. (2018). Prevalence of internet gaming disorder in adolescents: A meta-analysis across three decades. Scandinavian journal of psychology, 59(5), 524-531. doi.org/10.1111/sjop.12459.

33. Festl, R., Scharkow, M., \& Quandt, T. (2013). Problematic computer game use among adolescents, younger and older adults. Addiction, 108, 3, 592-599.

34. Gans H. J. (2009). Reflections on symbolic ethnicity. Ethnicities, 9, 1, 123-130.

35. Gentile, D. A., Choo, H., Liau, A., Sim, T., Li, D., Fung, D., \& Khoo, A. (2011). Pathological video game use among youths: a two-year longitudinal study. Pediatrics, 127, 2, 319-329.

36. Gentile, D. A., Swing, E. L., Lim, C. G. \& Khoo, A. (2012). Video Game Playing, Attention Problems, and Impulsiveness: Evidence of Bidirectional Causality. Psychology of Popular Media Culture, 1, 1, 6270.

37. Gainsbury, S. M. (2017). Cultural competence in the treatment of addictions: Theory, practice and evidence. Clinical psychology \& psychotherapy, 24, 4, 987-1001.

38. Giuliani, C., Tagliabue, S., \& Regalia, C. (2018). Psychological Well-Being, Multiple Identities, and Discrimination Among First and Second Generation Immigrant Muslims. Europe's Journal of Psychology, 14, 1, 66-87.

39. González-Bueso, V., Santamaría, J. J., Oliveras, I., Fernández, D., Montero, E., Baño, M., JiménezMurcia, S., Del Pino-Gutiérrez, A., \& Ribas, J. (2020). Internet Gaming Disorder Clustering Based on Personality Traits in Adolescents, and Its Relation with Comorbid Psychological Symptoms. International journal of environmental research and public health, 17, 5, 1516. doi:10.3390/ijerph17051516. 
40. Graham, S., \& Echols, L. (2018). Race and ethnicity in peer relations research. In W. M. Bukowski, B. Laursen, \& K. H. Rubin (Eds.), Handbook of peer interactions, relationships, and groups (p. 590-614). New York: The Guilford Press.

41. Guarnaccia, P., \& Lopez, S. (1998). Mental health and adjustment of immigrant and refugee children. Child Adolescent Psychiatric Clinics of North America, 7, 537-553.

42. Hadwiger A.N., Middleman A.B., \& Pitt P.D. (2019), Case series: gaming vs. eating-comorbidity of ARFID and IGD. Eating and Weight Disorders-Studies on Anorexia, Bulimia and Obesity, 24, 959-962.

43. Hayer, T., \& Griffiths, M. D. (2016). Gambling. In: T. Gullotta, R. Plant \& M. Evans (Eds.), Handbook of adolescent behavioral problems: Evidence-based approaches to prevention and treatment - 2nd ed. (pp. 539-558). New York: Springer.

44. Henneberger, A. K., Varga, S. M., Moudy, A., \& Tolan, P. H. (2016). Family functioning and high risk adolescents' aggressive behavior: Examining effects by ethnicity. Journal of youth and adolescence, $45,145-155$.

45. Hu, J.; Zhen, S.; Yu, C.; Zhang, Q.; Zhang, W. (2017). Sensation seeking and online gaming addiction in adolescents: A moderated mediation model of positive aective associations and impulsivity. Frontiers in Psychology, 8, 699.

46. Hussain, Z., \& Griffiths, M. D. (2009). Excessive use of massively multi-player online role-playing games: a pilot study. International Journal of Mental Health and Addiction, 7, 563-571.

47. ISTAT (2019). Cittadini e ICT. Report anno 2019. Disponibile online: https://www.istat.it/it/files//2019/12/Cittadini-e-ICT-2019.pdf

48. Jeong, E.J. \& Kim, D. W. (2011). Social activities, self-efficacy, game attitudes, and game addiction. Cyberpsychology, Behavior \& Social Networking, 14, 4, 213-221.

49. Jeong, H., Yim, H. W., Lee, S., Lee, H. K., Potenza, M. N., Jo, S., Son, H. J., \& Kim, G. (2020). Low selfcontrol and aggression exert serial mediation between inattention/hyperactivity problems and severity of internet gaming disorder features longitudinally among adolescents. Journal of Behavioral Addictions, 9, 2, 401-409.

50. Kouider, E. B., Koglin, U., \& Petermann, F. (2014). Emotional and behavioral problems in migrant children and adolescents in Europe: a systematic review. European child \& adolescent psychiatry, 23, 6, 373-391.

51. Kardefelt-Winther, D. (2014). Problematizing excessive online gaming and its psychological predictors. Computers in Human Behavior, 31, 118-122

52. Kien, C., Sommer, I., Faustmann, A., Gibson, L., Schneider, M., Krczal, E. \& Brattström, P. (2018). Prevalence of mental disorders in young refugees and asylum seekers in European Countries: a systematic review. European Child \& Adolescent Psychiatry, 28, 10, 1295-1310.

53. Kim, Y., Park, J. Y., Kim, S. B., Jung, I.-K., Lim, Y. S., \& Kim, J.-H. (2010). The effects of Internet addiction on the lifestyle and dietary behavior of Korean adolescents. Nutrition Research and Practice, 4(1), 51-57. 
54. Kim, Y.-R., Son, J.-W., Lee, S.-I., Shin, C.-J., Kim, S.-K., Ju, G., et al. (2012). Abnormal brain activation of adolescent internet addict in a ball-throwing animation task: Possible neural correlates of disembodiment revealed by fMRI. Progress in Neuro-Psychopharmacology \& Biological Psychiatry, 39(1), 88-95.

55. Kim M., Kim D., Bae A., Han D. H., Jeong B. (2020). Aberrant structural network of comorbid attention deficit/hyperactivity disorder is associated with addiction severity in internet gaming disorder. Neuroimage: Clinical, 27, 102263.

56. King, D. L., Delfabbro, P. H., \& Griffiths, M. D. (2011). The role of structural characteristics in problematic video game play: an empirical study. International Journal of Mental Health and Addiction, 9, 3, 320-333.

57. Kircaburun K., Demetrovics A., Grifiths M.D., Kiràly O., Kun B., Tosuntas B., (2020). Trait emotional intelligence and internet gaming disorder among gamers: the mediating role of online gaming motives and moderating role of age groups. Internationa journal of mental health and addiction, 18, 1446-1457.

58. Ko C., Yen J., Liu S., Huang C., Yen C. (2009). The associations between aggressive behaviors and internet addiction and online activities in adolescents. Journal of Adolescent Health, 44, 6, 598-605. doi: 10.1016/j.jadohealth.2008.11.011.

59. Kramer, M.A., van Veen, M.G., Op de Coul, E.L.M., Coutinho, R.A., Prins, M. (2014). Do sexual risk behaviour, risk perception and testing behaviour differ across generations of migrants? European Journal of Public Health, 24, 1:134-138.

60. Kraut, R., Patterson, M., Lundmark, V., Kiesler, S., Mukophadhyay, T., \& Scherlis, W. (1998). Internet paradox: A social technology that reduces social involvement and psychological well-being?. American psychologist, 53(9), 1017.

61. Kuss, D. J. (2013). Internet gaming addiction: current perspectives. Psychology Research and Behavior Management, 6, 125-137.

62. Kuss, D. J., \& Griffiths, M.D. (2012). Internet and gaming addiction: a systematic literature review of neuroimaging studies. Brain Sciences, 2, 347-374.

63. Kuss, D. J., Louws, J., \& Wiers, R. W. (2012). Online gaming addiction? Motives predict addictive play behavior in massively multiplayer online role-playing games. Cyberpsychology, Behavior and Social Networking 15, 9, 480-485.

64. Lam, L. T., Peng, Z., Mai, J., \& Jing, J. (2009). The association between internet addiction and selfinjurious behaviour among adolescents. Injury Prevention, 15(6), 403-408.

65. Lemmens, J. S., Valkenburg, P. M., \& Peter, J. (2011). Psychosocial causes and consequences of pathological gaming. Computers in Human Behavior, 27, 1, 144-152.

66. Lemmens J.S. \& Hendriks S.J.F. (2016). Addictive Online Games: Examining the Relationship Between Game Genres and Internet Gaming Disorder. Cyberpsychology, Behavior, and Social Networking, 19, 4, 270-276. doi: 10.1089/cyber.2015.0415. 
67. Li, D., Liau, A., \& Khoo, A. (2011). Examining the Influence of Actual-Ideal Self-Discrepancies, Depression, and Escapism, on Pathological Gaming Among Massively Multiplayer Online Adolescent Gamers. Cyberpsychology, Behavior, and Social Networking, 14, 9, 535-539.

68. Liau, A. K., Choo, H., Li, D., Gentile, D. A., Sim, T., \& Khoo, A. (2015). Pathological video-gaming among youth: a prospective study examining dynamic protective factors. Addiction Research \& Theory, 23(4), 301-308.

69. Lin, F., Zhou, Y., Du, Y., Qin, L., Zhao, Z., Xu, J., et al. (2012). Abnormal white matter integrity in adolescents with Internet addiction disorder: A tract-based spatial statistics study. Plos One, 7(1).

70. Liu, C.-Y. \& Kuo F.-Y. (2007). A study of Internet addiction through the Lens of the Interpersonal Theory. Cyberpsycology \& Behavior, 10 (6), 799-804.

71. Loton, D., Borkoles, E., Lubman, D., \& Polman, R. (2016). Video game addiction, engagement and symptoms of stress, depression and anxiety: The mediating role of coping. International Journal of Mental Health and Addiction, 14(4), 565-578.

72. Maftei A., Enea V. (2020). Symptoms of internet gaming disorder and parenting styles in Romanian Adolescents. Psihologija, 53, 3, 307-318.

73. Marino C., Canale N., Altoè G., \& Spada M. M. (2020). Social anxiety and internet gaming disorder: the role of motives and metacognitions. Journal of Behavioral Addictions, 9, 3, 617-628.

74. Milani, L., La Torre, G., Fiore, M., Grumi, S., Gentile, D. A., Ferrante, M., Miccoli, S., \& Di Blasio, P. (2018). Internet Gaming Addiction in Adolescence: risk factors and maladjustment correlates. International Journal of Mental Health \& Addiction, 16(4), 888-904.

75. Milani, L., Osualdella, D., \& Di Blasio, P. (2009). Quality of interpersonal relationships and problematic Internet use in adolescence. CyberPsychology \& Behavior, 12(6), 681-684.

76. Morahan-Martin, J. \& Schumacher, P. (2000). Incidence and correlates of pathological Internet use among college students. Computers in Human Behavior, 16, 13-29.

77. Motto-Stefanidi, F. (2018). Resilience among immigrant youth: The role of culture, development and acculturation. Developmental Review, 50, 99-109.

78. Motto-Stefanidi, F., Pavlopoulos, V., \& Asendorpf, J. B. (2018). Immigrant youth acculturation and perceived discrimination: longitudinal mediation by immigrant peers' acceptance/rejection. Journal of Applied Developmental Psychology, 59, 36-45.

79. Mentzoni, R. A., Brunborg, G. S., Molde, H., Myrseth, H., Skouverøe, K. J. M., Hetland, J., \& Pallesen, S. (2011). Problematic video game use: Estimated prevalence and associations with mental and physical health. Cyberpsychology, Behavior, and Social Networking, 14, 10, 591-596.

80. Müller, K.W., Janikian, M., Dreier, M., Wölflin, K., Beutel, M. E., Tzavara, C., Richardson, C. \& Tsitsika A. (2015). Regular gaming behavior and internet gaming disorder in European adolescents: results from a cross-national representative survey of prevalence, predictors, and psychopathological correlates. European Child \& Adolescent Psychiatry, 24, 565-574.

81. Musetti A., Mancini T., Corsano P., Santoro G., Cavallini M. C. \& Schimmenti A. (2019). Maladaptive personality functioning and psychopathological symptoms in problematic video game players: a 
person-centered approach. Frontiers in Psychology, 10 (2559), pp. 1-14.

doi:10.3389/fpsyg.2019.02559

82. Nakash, O., Nagar, M., Shoshani, A., Zubida, H., Harper, R.A. (2012). The effect of acculturation and discrimination on mental health symptoms and risk behaviors among adolescent migrants in Israel. Cultural Diversity and Ethnic Minority Psychology. 2012;18, 3:228-238.

83. Neto, F. (1995). Predictors of satisfaction with life among second generation migrants. Social Indicators Research, 35, 1, 93-116.Newzoo (2020). Global Games Market Report. Available online: https://newzoo.com/

84. Ostinelli E., Zangani C., Giordano B., Maestri D., Gambini A., Purgato M., (2021). Depressive symptoms and depression in individuals with internet gaming disorder: A systematic review and meta-analysis. Journal of Affective Disorders, 284, 136-142.

85. Pace, U., D'Urso, G., \& Zappulla, C. (2019). Internalizing problems as a mediator in the relationship between low effortful control and internet abuse in adolescence: A three-wave longitudinal study. Computers in Human Behavior, 92, 47-54.

86. Park, M.-H., Park, E. J., Choi, J., Chai, S., Lee, J.-H., Lee, C., et al. (2011). Preliminary study of Internet addiction and cognitive function in adolescents based on IQ tests. Psychiatry Research, 190(2-3), 275-281.

87. Pascoe, E., \& Richman, L. S. (2009). Perceived discrimination and health: a meta-analytic review. Psychological bulletin, 135, 4, 531-54.

88. Paschke, K., Austermann, M. I., Simon-Kutscher, K., \& Thomasius, R. (2021). Adolescent gaming and social media usage before and during the COVID-19 pandemic. Sucht, 67(1), 13-22.

89. Paulus, F.W., Ohmann, S., von Gontard, A. and Popow, C. (2018), Internet gaming disorder in children and adolescents: a systematic review. Developmental Medicine and Child Neurology, 60, 645-659. doi: $10.1111 /$ dmcn.13754.

90. Portes, A., \& Rumbaut, R. G. (2005). Introduction: The second generation and the children of immigrants longitudinal study. Ethnic and Racial Studies, 28, 6, 983-999.

91. Portes, A., \& Rumbaut, R.G. (2001). Legacies. The story of the immigrant second generation. Berkeley-New York: University of California Press-Russel Sage Foundation.

92. Rehbein, F., Psych, G., Kleimann, M., Mediasci, G., \& Mößle, T. (2010). Prevalence and risk factors of video game dependency in adolescence: results of a German nationwide survey. Cyberpsychology, Behavior and Social Networking, 13, 3, 269-277.

93. Servidio, R., Bartolo, M. G., Palermiti, A. L., \& Costabile, A. (2021). Fear of COVID-19, depression, anxiety, and their association with Internet addiction disorder in a sample of Italian students. Journal of Affective Disorders Reports, 4, 100097.

94. Snodgrass, J. G, Dengah, H. J., Lacy, M.G. \& Fagan, J. (2013). A formal anthropological view of motivation models of problematic MMO play: Achievement, social, and immersion factors on the context of culture. Transcultural Psychiatry, 50, 2, 235-262. 
95. Snodgrass J. G., Bagwell A., Patry J. M., Dengah H. J., Smarr-Foster C., Van Ostenburg M., Lacy M. (2018). The partial truths of compensatory and poor-get-poorer internet use theories: more highly involved videogame players experience greater psychosocial benefits, Computers in Human Behavior, 78, 10-25. https://doi.org/10.1016/j.chb.2017.09.020

96. Steenkamp, J. B. E., Baumgartner, H. (1998). Assessing measurement invariance in cross-national consumer research, Journal of Consumer Research, 25, 78-90. https://doi.org/10.1086/209528

97. Stevens, G. W., \& Vollebergh, W. A. (2008). Mental health in migrant children. Journal of child psychology and psychiatry, 49, 3, 276-294.

98. Stinchfield, R. (2000). Gambling and correlates of gambling among Minnesota public school students. Journal of Gambling Studies, 16(2-3), 153-173.

99. Su W., Han X. Yu H., Wu Y., Potenza M. N. (2019). Do men become addicted to internet gaming and women to social media? A meta-analysis involving 34 global jurisdictions. Computers in Human Behavior, 99, 86-100.

100. Sun, Y., Li, Y., Bao, Y., Meng, S., Sun, Y., Schumann, G., ... \& Shi, J. (2020). Brief report: increased addictive internet and substance use behavior during the COVID-19 pandemic in China. The American Journal on Addictions, 29(4), 268-270.

101. Sugaya, N., Shirasaka, T., Takahashi, K. \& Kanda H. (2019). Bio-psychosocial factors of children and adolescents with internet gaming disorder: a systematic review. BioPsychoSocial Medicine 13(3). doi:10.1186/s13030-019-0144-5.

102. Tabor, A. S., \& Milfont, T. L. (2011). Migration change model: Exploring the process of migration on a psychological level. International Journal of Intercultural Relations, 35(6), 818-832. https://doi.org/10.1016/j.jijintrel.2010.11.013.

103. Tang, J., Ma, Y., Lewis, S. P., Chen, R., Clifford, A., Ammerman, B. A., Gazimbi, M. M., Byrne, A., Wu, Y., Lu, X., Chang, H., Kang, C., Tiemeier, H., \& Yu, Y. (2020). Association of Internet Addiction With Nonsuicidal Self-injury Among Adolescents in China. JAMA network open, 3, 6, e206863. Doi:10.1001/jamanetworkopen.2020.6863

104. Triberti, S., Milani, L., Villani, D., Grumi, S., Peracchia, S., Curcio, G., \& Riva, G. (2018). What matters is when you play: investigating the relationship between video games addiction and time spent playing over specific day phases. Addictive Behaviors Reports, 8, 185-188.

105. Tsitsika, A., Critselis, E., Louizou, A., Janikian, M., Freskou, A., Marangou, E., et al. (2011). Determinants of Internet addiction among adolescents: A case-control study. The Scientific World Journal, 11, 866-874.

106. Valtolina, G.G. (2013). Improving children's rights in migration across Europe. In G.G. Valtolina (Ed.), Migrant Children in Europe, Amsterdam: IOS Press, pp. 1-15.

107. Valtolina, G. G., Boerchi, D. (2019). L'inserimento socio-lavorativo dei minori stranieri non accompagnati in Italia. Studi Emigrazione/Migration Studies, 56, 58-72.

108. Van Rooij, A. J., Kuss, D. J., Griffiths, M. D., Shorter, G. W., Schoenmakers, M. T., \& Van de Mheen, D. (2014). The (co-)occurrence of problematic video gaming, substance use, and psychosocial 
problems in adolescents. Journal of Behavioral Addictions, 3, 3, 157-165.

109. Verkuyten, M. (1998). Perceived discrimination and self-esteem among ethnic minority adolescents, Journal of Social Psychology, 138, 4, 479-493.

110. Walsh, S., Shulman, S., \& Maurer, O. (2008). Immigration distress, mental health status and coping among young immigrants: A 1-year follow-up study. International Journal of Intercultural Relations, $32,5,371-384$.

111. Walther, B., Morgenstern, M., \& Hanewinkel, R. (2012). Co-occurrence of addictive behaviors: Personality factors related to substance use, gambling and computer gaming. European Addiction Research, 18, 4, 167-174.

112. Wang, C. W., Ho, R. T., Chan, C. L., \& Tse, S. (2015). Exploring personality characteristics of Chinese adolescents with internet-related addictive behaviors: Trait differences for gaming addiction and social networking addiction. Addictive Behaviors, 42, 32-35.

113. Wang, C., Wu, Y., Su, C., Lin, P., Ko, C., \& Yen, J. (2017). Association between Internet gaming disorder and generalized anxiety disorder, Journal of Behavioral Addictions, 6, 4, 564-571

114. Wang, M., Zeng, N., Zheng, H., Du, X., Potenza, M., \& Dong, G. (2020). Altered effective connectivity from the pregenual anterior cingulate cortex to the laterobasal amygdala mediates the relationship between internet gaming disorder and loneliness. Psychological Medicine, 1-10. doi:10.1017/S0033291720002366.

115. Wardle, H., Bramley, S., Norrie, C., \& Manthorpe, J. (2019). What do we know about gambling-related harm affecting migrants and migrant communities? A rapid review. Addictive behaviors, 93, 180193.

116. Wartberg L., Kriston L., \& Thomasius R. (2020). Internet gaming disorder and problematic social media use in a representative sample of German adolescents: prevalence estimates, comorbid depressive symptoms and related psychosocial aspects. Computers in Human Behavior, 103, 31-36.

117. Wasserstein, R. L, \& Lazar, N. A. (2016) The ASA's Statement on p-Values: Context, Process, and Purpose. The American Statistician, 70, 2, 129-133.

118. Wenzel, H. G., Bakken, I. J., Johansson, A., Götestam, K. G., \& Øren, A. (2009). Excessive computer game playing among Norwegian adults: Self-reported consequences of playing and association with mental health problems. Psychological Reports, 105, 3, 1237-1247.

119. Yakushko, O., Watson, M., \& Thompson, S. (2008). Stress and coping in the lives of recent immigrants and refugees: Considerations for counseling. International Journal for the Advancement of Counselling, 30(3), 167. doi: 10.1007/s10447-008-9054-0.

120. Yang X., Jiang X., Mo PK-H., Cai Y., Ma L., Lau JT-F. (2020). Prevalence and Interpersonal Correlates of Internet Gaming Disorders among Chinese Adolescents. International Journal of Environmental Research and Public Health, 17, 2, 579. doi: 10.3390/ijerph17020579

121. Yellowlees, P. M., \& Marks, S. (2007). Problematic Internet use or Internet addiction?. Computers in human behavior, 23(3), 1447-1453. 
122. Young, K. S. (1998). Internet addiction: the emergence of a new clinical disorder. Cyberpsychology \& Behavior, 1(3), 237-244.

123. Young, K. S., \& Rodgers, R. C. (1998, April). Internet addiction: Personality traits associated with its development. In 69th annual meeting of the Eastern Psychological Association (pp. 40-50).

124. Yu Y., Yang X., Wang S., Wang H., Chang R., Tsmlag L., Zhang S., Xu C., Yu X., Cai Y., Lau J.T.F. (2020). Serial multiple mediation of the association between internet gaming disorder and suicidal ideation by insomnia and depression in adolescents in Shanghai. BMC Psychiatry, 20, 460, 1-9. doi:10.1186/s12888-020-02870-z. 